\section{Rules of Zoological Nomenclature}

Such cases of the abuse of the rules of zoological nomenclature as are indicated by Prof. W. Garstang in Nature of September 9 indicate a failure in the functioning of the present rules which is an ever present danger and hindrance to the work for which systematic researches exist. The existing rule that no names shall bo changed if the result will be greater confusion than uniformity needs enforcement. At present, this can only bo dono by a long and cumbrous procedure which has resulted in comparatively few, § few hundred, nomina conservanda, and those generally. only of common genera, and very few species. It is also unfortunato that this remedy comes after the damage has been done. The position needs something much more rapid and thorough which, under the present scheme, would mean the appointment of whole-time searchers in each group, who would present lists of a thousand or so names annually to a committee of superhuman patience. Such a schemo is utterly impossible.

Are there any alternatives? I suggest that the old rules, having served well in the old days, should now be altered radically. Consider how different is our position now. We have a vast body of system. atic literature, upon much of which the most careful labour of the most skilled observers has been freely and generously expended. This vast labour has not been, for the most part, an end in itself; its essential value is to bo the foundation of such subjects as ecology and genotics. It must therefore bo regarded as an essential tool, to bo altered and adjusted only when wo aro compelled by diro necessity. What would become of a factory in which the machinery might bo adjusted without reference to the work of the factory as a whole? This is exactly the danger the framers of the rules of nomenclature had in mind and tried to avoid, but which insistence on the letter of the law, and neglect of its spirit, has made rampant.

I venture, therefore, to recall a suggestion I made more than thirty years ago, which was approved by the lato Sir Arthur Shipley and published in Natune, namely, that a small committeo of experts in each group should select the most useful books in each, the names in which should be unalterable for any literary or priority reasons. Conversation with my friends shows that I must enlargo a little; it seems to bo taken that I mean the establishment of a kind of Holy Writ-an idea abhorrent to science. The committee on group $Z$, say, decides that the most useful books in that group are $A$. . H dated, say, 1850 to 1920 (for obvious reasons no book of very recent date could bo included). It is then found that the author of book $E$ published excellent descriptions of a number of species, but took littlo trouble over synonymy, and some of his species are the same, or, in the opinion of subsequent authors, should bo reckoned as varieties of species described by the authors of $A, B$ or $C$. The names used by the latter authors therefore have priority, and are to be used; research into literature, once important and useful, but now only of historic value, of older date than that of the book $A$, will not be allowed to upset $E$ 's names. Criticism founded on new knowledge, or even individual views of the relationship of species and genera, would be as free as they aro now. In this way thousands of names, species as well as generic, could be saved by one year's work.

Something might also be done by ignoring the so-called work of those who change names on trivial grounds, as sinners against the workers for whose convenience they, in fact, exist. The first necessity is that a worker who is not a specialist in systematics shall be able to get the description, variation and distribution of the species with which he is dealing with the least possible difficulty and the greatest possible certainty. Again I repeat, this is the end for which systematists work, and those who would put difficulties and delays in the way should receive every possible discouragement from all scientific workers.

Universitets Zoologiske Museum,

Crtril Crosslaxd. Kobenharn.

\section{Birds of Britain}

Is the review of the "Handbook of British Birds", vol. 3, in Nature of October 21, p. 691, there are some criticisms which require an answer. Some are merely matters of personal experience. 'S. G.' has never seen bracken used for nesting by tho golden eagle, but others have. Nests in trees have always been a small minority, except in one restricted district. As to the share of the sexes in providing food for the young, H. B. Macpherson, who watched a nest for long periods in 1909, records in his diary no fower than twenty occasions on which the female brought food to the nest. $A$. Brook in his diary states that the hen brought a grouse and a young hare to the nest on June 14. While I agree, and have stated in the "Handbook", that the male takes the chief part in this work, it is impossible to ignore Mracpherson's evidenco, and 'S. G.', to whom I mentioned this fact, could give no explanation of the discrepancy.

Nry I quote one sentence from 'S. G.'s' own notes ? "I believe that the cock [sic] must have come twice to the eyrio unperceived by me, for when I left the hide there were two more grouse in the nest." The eyrio in question was ten yards from where 'S. G.' kept watch.

F. C. R. Jourdais.

Whitekirk,

Southbourne,

Bournemouth.

Oct. 25.

Dunisg the past thirty-five years I have visited more than a hiundred golden eagles' eyries in the Highlands of Scotland, yet I have never seen bracken used as a nesting material. This shows, I think conclusively, that bracken must be very rarely used.

Eyries in trees are certainly not in a "small minority". I used to know of at least seven pairs of golden eagles (some of them have now been driven away by the attentions of egg collectors) which almost invariably nested in trees. I should say, indeed, that tree-nesting golden eagles are in the majority in the Central Highlands although in a minority in the Western Highlands; yet even in the west I know of several eagles' eyries in trees.

During the years 1924-36, my wife and I watched for more than three hundred hours, throughout the day and night, at both rock and tree eyries of golden eagles, yet we never saw the female golden eagle carry in food. It was she who almost always fed the young, but the food was aluays brought by the male. 'I'his seems to show that at Mr. H. B. Nacpherson's eyrie (he watched, I believe, only at one eyrie) the bringing of food by the female was exceptional.

S. G. 